\title{
Effect of Bingo Game Instructional Strategy on Pupils' Achievement in Mathematics in Public Primary Schools in Oyo State, Nigeria
}

\author{
Adedeji Tella \\ Department of Science and Technology Education, University of Ibadan, Ibadan, Nigeria \\ Felicia Motunrayo Fatoki \\ Federal School of Statistics, Ibadan, Nigeria
}

\begin{abstract}
This study determined the effect of Bingo game instructional strategy on Pupils' mathematics Achievements of public primary schools in Oyo state, Nigeria. One hundred and twelve public primary school grade 3 pupils participated in the study. This study adopted the pretest-posttest control group quasi-experimental design with a $2 x 3$ factorial matrix. The study deployed Bingo strategy as different patterns that were designed to create fun and variety in teaching mathematics. The pretest was administered before the teaching using Bingo strategy, while posttest was administered immediately after the treatment (Bingo strategy). The control group were left with conventional teaching without any manipulation. Simple random sampling was used to select four primary schools from two local government area in Oyo State, Nigeria. Two constructed standardized and validated instruments by the researchers were used for the study: Pupils mathematics Achievement Test $(\mathrm{r}=0.81)$ and Quantitative Ability Test $(\mathrm{r}=0.69)$. The treatment lasted four weeks. The data were analyzed using Analysis of covariance at 0.05 level of significance. The result revealed that there was a significant main effect of Bingo on pupils achievement in mathematics $\left(\mathrm{F}_{(1,110)}=3.327\right.$; partial $\eta^{2}=$ $0.131)$. There was a significance main effect of quantitative ability $\left(\mathrm{F}_{(1,110)}=0.603\right.$; partial $\left.\eta^{2}=0.206\right)$ on pupils achievement in mathematics. The high quantitative ability pupils (56.904) benefited from the treatment package more than their counterpart (31.451). There was significant two-way interaction effect of Bingo game and quantitative ability of the participants $\left(\mathrm{F}_{(2,106)}=1.543\right.$; partial $\left.\eta^{2}=0.214\right)$ in favour of high quantitative ability pupils from Bingo game instructional strategy. The participants in Bingo game (14.07) had a higher mean value than their counterparts in the control (6.61). Bingo game instructional strategy improved pupils' achievement in mathematics. Primary school mathematics teachers should try to adopt this strategy in their teaching delivery.
\end{abstract}

Keywords: Bingo game strategy, Primary grade 3 pupils, mathematics achievement and quantitative ability

\section{Introduction}

Mathematics for level 3 pupils involves problem solving in the area of number work known as numeracy such as the measurement of shapes which includes calculating their perimeter, area and volume. It also involves simple calculation with rational numbers using real life problems. The skills acquired through the above concepts are necessary and sufficient in helping students to be successful in everyday math experiences that include accuracy, precision, aptitude, thinking, logic, and reasoning. Mathematics is used throughout the world as an essential tool in many fields including natural science, engineering, medicine, finance and the social sciences. In Nigeria, mathematics is taught from pre-primary school in order to provide the foundation on which later mathematical knowledge is built (Okafor and Anaduaka, 2013). These authors claim that mathematics encourages the habit of self-reliance and assists learners to 
think and solve their problems themselves. Mathematics is all around us, in everything we do. It is the building block for everything in our daily lives, including mobile devices, architecture (ancient and modern), art, money, engineering, and even sports. Osokoya (2005) observed that mathematics is the basic science from which fundamental knowledge and understanding of the other sciences is cultivated for any sustainable scientific tradition and technologies development in Nigeria. However, preliminary investigation, by the researchers, revealed that mathematics teachers' inappropriate teaching strategies hindered the teaching and learning of mathematics at the primary school level in Oyo State, Nigeria. They pointed out the attributed problems hindering mathematics teaching and learning in Nigerian schools to teachers' inability to help students learn mathematics in a meaningful way (Adetunji (2000) and Akinsola (1999).

Mass failure in mathematics examination by students in West African Examinations and internal examinations has been traced to many factors. These include lack of adequate teaching materials, poor presentation by teachers, uncooperative attitude of the students and large class

size (Ifamuyiwa, 2005). Other reasons are; shortage of qualified mathematics teachers (Akinsola, 2000), shortage of mathematics textbooks (Onabanjo, 2004) to mention but a few. From the aforementioned reasons, West African Examination Council (WAEC) Chief Examiner's Report (2015) suggested that students' performance in mathematics could be improved through designing a meaningful and innovative teaching strategy. According to the report, teachers should help students develop interest in mathematics by reducing the abstractness of mathematics, and hence remove their apathy and fears in the subject.

From the early years' past, children at the primary school level have been learning through many methods and techniques (Shofoyeke, 2012). Awofala, Fatade \& Ola-Oluwa (2012) also asserted that teachers should endeavour to adopt a variety of appropriate strategies to teaching pupils mathematics in classroom. Some of these strategies include using diagrams, looking for patterns, listing all possibilities, trying special values or cases, working backward, guessing and checking, creating an equivalent problem and creating a simpler problem. Mustafa, Khan \& Ullah (2011) and Haramati (2000) expressed active learning in which Bingo game instructional strategy is one of the strategies that creates joy, excitement, and love for learning which gaming often creates.

Akinboye (1996) expressed that learning involves acquisition of better ways of doing things through changes in behaviour that results from real-life experiences This real learning must involve both teacher and learner in order to enhance effective learning. Thus, it becomes pertinent to look for strategies that could be used in order to effectively have higher mathematics learning outcomes in order to eradicate the problems of teaching and learning of mathematics in the past in primary schools. This study is anchored to Game Theory to teach the concepts of length, perimeter, shapes and figures through gaming. Game theory has been applied to contexts in business, biology, physics, chemistry, and other disciplines. Based on this, the Bingo game instructional strategy has been identified through the literature as a promising strategy to teach pupils mathematics (Coco, Woodward, Shaw, Cody, Lupton and Peake, 2001; Pulos \& Sneider, 1994).

Mathematics games have been detected to be one of the learning strategies that enable pupils to 
learn mathematics without stress. Obodo (1997) described mathematics games as activity in the form of puzzles, magic tricks, fallacies, paradoxes or any type of mathematics which provides amusement or curiosity and stimulates mathematics thinking, excitement in the spirit of competition and cooperation. Also, games enable interest of students to be aroused towards the learning of the subject. Several researchers such as Coco, Woodward, Shaw, Cody, Lupton and Peake, 2001 have attested to the effects of use of games instructional strategy in achieving instructional objectives at the primary and secondary school levels. Corti (2006) expressed that games engage people psychologically, physiologically and emotionally. He further added that games help to create and provide an environment for the users to learn the process of explanation, description, construction, assessment and the evaluation of advanced problems solving skills. In its own view, the National Council of Teachers of mathematics (NCTM, 2007) state that game is an aspect of mathematics used in developing the four thinking mathematics standards: problem solving, communication, reasoning and connections. These skills are needed most in real life. Furthermore, instructional games create a new learning culture that better corresponds with "pupils" habits and interests (Prensky, 2001). Mustafa, Khan, and Ullah (2011) expressed active learning as the creation of joy, excitement, and love for learning which are created through games. Mansureh, Atsusi and Haiyan (2010), submitted that instructional games are thought to be effective tools for teaching difficult and complex procedures because they use action instead of explanation, create personal motivation and satisfaction, accommodate multiple learning styles and skills, reinforce mastery skills and provide interactive and decision-making contexts (Charles and McAlister, 2004; Holland, Jenkins and Squire, 2002). Mathematical games which can also be called educational games have been defined as an enjoyable social activity with goals, rules, and educational objectives (Stephen and Cary, 1994). Learning through games also provides immediate feedback to pupils. While learning games, the content can be taught and rehearsed, a positive atmosphere can be created and social interactions can be promoted in the classroom (Pehkonen, 1993). Games support many of the components of flow such as clear goals, direct and immediate feedback, balance between ability level and challenge, and sense of control. These components can increase student engagement, and student engagement is strongly associated with student achievement (Shute, Ventura, Bauer and Zapata-Rivera, 2009). Games contain the pieces necessary to engage students and help them enter a state of flow (Csikszentmihalyi, 1990) where they are fully immersed in their learning environment and energized and focused on the activity

they are involved in. Ke and Grabowski (2007) in their study on "Gameplaying for mathematics learning: Cooperative or not?" found results that "students who played games had a better mathematics performance than those who received paper-based drills".

Bingo game instructional strategy is description where all of the possible Bingo numbers are displayed on an electronic reader board in the Bingo game room. At the beginning of each game, an electronic random number generator selects a predetermine groups of Bingo numbers to be blue, green and red numbers. All of the other remaining numbers are yellow numbers for that particular game of Bingo. When a player achieves a Bingo, the player wins certain pre-established payout depending upon whether the player has an all "blue" Bingo, and all "green" Bingo, and all "red" Bingo and all "yellow" Bingo or 
any other Bingo (which would be a "mix" colour Bingo). The "all blue" Bingo receives the highest payout, the "all green" Bingo receives the next highest payout, the "all red" Bingo receives the next highest payout, the all "yellow" receives the next highest payout and the smallest payout is awarded to a regular "mix" colour Bingo. Therefore, a Bingo game enables pupils to develop cognitive skills such as analytical, aptitude, and problem-solving. This could be possible owing to the development of aptitude skill, computational skill, and mathematical ability that can be enhanced during the teaching and learning of mathematics using Bingo game. Is also promotes the spirit of sportsmanship as neither a loser or winner during it deployment. What is paramount in using it is simply to gain knowledge.

Apart from innovative strategy such as Bingo game in teaching pupils' mathematics, other variables such as quantitative ability, gender, socio-economic factor, personality traits, among others, often intervene the traditional teaching and learning of mathematics. Bingo overcomes these factors to ensure that real learning can take place for all.

This study then considered quantitative ability as a moderating variable interacting between the intervention and dependent variable. Quantitative ability can be expressed as the ability to solve numerical and mathematical calculation accurately and as quick as possible. It has to do with executing tasks which are related to manipulation of figures or handling of numbers. The quantitative aptitude test measures the numerical ability and accuracy in mathematical calculations. Adu, Ojelabi \& Adeyanju (2009) describe quantitative ability as the ability to execute tasks which are related to the handling of numbers. Some of its synonyms are numerical ability, numerical aptitude, mathematical ability and figural ability mathematical skill.

Game instructional strategy has been steadily growing for the past several years. There is a growing interest in gaming in classroom to engage students (Vlachopoulos \& Makri, 2017). Muzzy Lane Software Company (2002) was one of the pioneers of Game Based Learning who expressed that well designed games with education experiences are challenging but achievable. Games should present players with challenges that are matched to their skill level in order to maximize the impact of educational games (Kiili, 2005).

In an educational game, however, the price of failure is lower (Gee, 2005). Students can take risks and quickly learn from their mistakes. Effective games provide feedback that is "(1) clear and unobtrusive, and (2) immediately responsive to the player's actions" (Rigby and Ryan, 2007, p. 8). The feedback also helps reinforce motivation (Jones and Issroff, 2005). Students are able to adapt to the feedback, and the game continues to adapt to the student. In order to really evaluate the efficacy of games, researchers need to consider more nuanced features such as the length of game play and the content, structure, and mechanics of the games (Khoo and Gentile, 2005).

Mathematics competence at the primary and secondary levels is a critical determinant of postsecondary education and career choices. Over the years, pupils' mathematics achievements from the primary school level have not been encouraging due to teachers' uses of ineffective methods (Akinsola \& Tella, 2003). Appropriate use of relevant instructional strategies in the delivery of mathematics instructions and developing pupils' attitudes positively towards it from early primary school classes are the solutions 
to this problem. In addition to various instructional strategies and appropriate uses of instructional materials, the use of games instructional strategy also needs to be adopted to replace the conventional instructions in order that the pupils could enjoy effective delivery of relevant skills in mathematics. Hence this study determines the effects of Bingo game instructional strategy on pupils' achievement in mathematics in public primary schools in Oyo state, Nigeria with the view to enhance and promote pupils' understanding, comprehension and assimilation of length, perimeter, shapes and figures. The moderating effects of quantitative ability were also examined

\section{Objectives of the study}

Specifically, the study determined the effect of Bingo game instructional strategy on pupils' mathematics achievement in public primary schools, Oyo state. The study also examined the moderating effect of quantitative ability on the dependent variable. The quantitative ability as one among many extraneous variables (gender, school type, self-concept, attitude) became necessary to examine its effect on pupils' achievement base on its strength as reviewed by empirical findings (Adu et al., 2009).

From the stated objectives of the study, the following research questions were raised:

1. What is the difference between Bingo game instructional strategy group and the conventional strategy group (control) in terms of pupils' achievement in length, perimeter, shapes and figures?

2. What is the difference between pupils that were exposed to Bingo game instructional strategy and conventional strategy group (control) in terms of pupils' quantitative ability?

3. What is the interaction effect of Bingo game instructional strategy and quantitative ability on pupils' achievement in length, perimeter, shapes and figures?

\section{Hypotheses}

$\mathrm{H}_{0} 1$ : There is no significant main effect Bingo game instructional strategy on pupils' achievement in mathematics

$\mathrm{H}_{0} 2$ : There is no significance main effect of quantitative ability on pupils' achievement in mathematics

$\mathrm{H}_{0} 3$ : There is no significance two-way interaction effect of Bingo game instructional strategy and quantitative ability on pupils' achievement in mathematics

\section{Methodology}

Bingo game is a mathematical game that helps pupils to improve their cognition skills. The figures and the expressions below are written on a big cardboard. Small cards were distributed to each pupil in the group except the leader. The fastest pupils place the card on the square box. The first pupil to place the small squares on a row, a column or a diagonal is called the winner and the pupils in the group shout BINGOOO!!! Meaning that, that pupil is the winner in the group he or she belongs to.

The study adopted the pretest - posttest control group quasi-experimental design with a $2 \times 3$ factorial matrix. The pretest was administered before the teaching using Bingo strategy, while posttest was 
administered immediately after the treatment (Bingo strategy). The control group were left with conventional teaching without any manipulation. The row consisted of Bingo game instructional strategy and conventional method (control group), that is teaching without using Bingo game) respectively. The row was crossed with quantitative ability (the ability to solve numerical and mathematical calculation accurately and as quick as possible) varied at three levels (high, medium and low). One hundred twelve participants were public primary level three pupils randomly drawn from four public primary schools in Akinyele and Ibadan North-East local government areas of Oyo state during the 2016 academic session. Two schools each were assigned to experimental groups and two schools each were assigned to control groups respectively. The participants consisted of pupils who had consistent school records of low mathematics achievement for two terms. Out of these 112 participants, 36 (32.1\%) were males while 76 (67.9\%) were females. The mean age of the participants was $5.37 \pm 1.50$ Standard Deviation. Pupils' mathematics Achievement Test (PMAT) and Quantitative Ability Test (QAT) were used to collect data. Pupils Mathematics Achievement Test (PMAT)

- The PMAT was developed by researchers in form of a multiple-choice test for primary level three pupils' mathematics curriculum and scheme of work. The test consists of two sections. Section A is designed for personal data of the pupils. Section B consists of 20 multiple choice questions with an objective test format. PMAT was developed to measure the pupils' acquisition level in length of objects/shapes and distances and perimeter of plane shapes like notebooks, pupils' desks, classroom doors and windows. All the questions are to be answered by the participants within an hour. Example of the items in the Test was: 1) $2 \mathrm{~m} 53 \mathrm{~cm}$ is equal to $\mathrm{cm}$; 2) 2 rectangles; 3) $132 \mathrm{~cm}=\ldots \ldots \mathrm{m} . \ldots . . . \mathrm{cm} ; 4)$ A square. The difficulty index is used in this context as the probability that pupils will answer a test correctly, generally more difficult items have a low percentage or $\mathrm{p}$ value, while discriminative index is the basic measure of the validity of items. Is a measure of an item's ability to discriminates between people which scored high on the total test of PMAT and those who score low of 0.53 and the discrimination index of 0.70 were obtained while the KuderRichardson formula 20 was used to measure the internal consistency and 0.81 was obtained.

\section{Quantitative Ability Test (QAT)}

It is a multiple-choice objective test which consists of 20 items. The instrument was designed by the researchers in relation to the content of the study to assess pupils' quantitative ability based on the existing similar test. However, its psychometric property was duly established through validity, reliability, score ability, and suitability. This was made up of 20 multiple choice items with four options (A-D). The face and content validation reduced the items from 30 to 20 after giving the test to three teachers in primary schools for scrutiny. Kuder-Richardson formula 20 was used to measure the internal consistency and coefficient of 0.69 was obtained. Example of the items in the Test were: which of these numbers is even:

$1,2,3,4,5,6,7,8,9,0$ ?; simplify; $\frac{2}{5}$ of 35 ; I have fifty naira, I bought two rulers that cost six naira each. How much do 1 have left? 


\section{Treatment Procedures}

\section{Experimental Group: Bingo Game Instructional Strategy Guide.}

After the topic (length and perimeter of shapes) was taught in the selected schools, then the game was played by the pupils in the two schools used for treatment (experimental). The figures and question as shown on pages $10-11$ was written and drawn on small cardboards each. These were kept inside a carton. Then the solution to each of those questions were drawn on the big cardboard or written on the bid cardboard. The pupils are divided into groups with one group leader each. Each of the members in the group was given a small piece of card to hold. the group leader then pick a question and show it to members of his/her group so that the first pupil to know the correct answer will place it, on the cardboard being held, on the portion that had the correct answer and the group leader will shout BINGO!!!!!. This will continue until all the members of the group had played the game round. Each of the groups play the game at the same time and pace until the class teacher or research assistants stop them. This is a further explanation of how the game was prepared and played:

1. The figures and the expressions below are written on a big cardboard.

2. Small cards were distributed to each pupil in the group except the leader. The fastest pupils place the card on the square box. The first pupil to place the small squares on a row, a column or a diagonal is called the group leader of the winner group shout BINGOOO!!! Meaning that, that pupil is the winner in the group he or she belongs to.

3. The game will then be restarted by choosing another leader for each group.

Pupils were left to play the game in groups while the teachers only ensure orderliness of pupils in playing the game.

\section{Bingo Game Instructional Strategy Lesson Notes.}

Lesson notes on the topic (length and perimeter of shapes) to be used for the study by the researchers. The lesson notes for the experimental group contains instructional materials showing shapes like rectangles, triangles and squares of different dimensions. Teacher also demonstrated uses of rulers to measure lengths and perimeter of shapes. After this Bingo game was played using (mathematics) games material as previously discussed.

The topic was introduced to the class teachers in the schools selected. Two days were used for distributing the games materials and training the class teachers as research assistants/facilitators on the game procedures in the selected schools and two days were used for ensuring understanding of the games for the classroom teachers (as contained in the Bingo game instructional strategy guide, while the implementation is contained in the activity 1). The pupils in this group were taught measurement of length and perimeter of shapes using conventional instruction for three days and the fourth day was used for summary and evaluation.

The fifth day, the class teacher introduced to their pupils how to play the game. The teachers played the game with the whole class first. Then the pupils were divided into groups of six pupils per group. After this the pupils were allowed to choose a leader for each of their groups. 
Activity 1:

1. The figures and the expressions below are written on a big cardboard.

2. Small cards were distributed to each pupil in the group except the leader. The fastest pupils place the card on the square box. The first pupil to place the small squares on a row, a column or a diagonal is called the winner and the pupils in the group shout BINGOOO!!! Meaning that, that pupil is the winner in the group he or she belongs to.

3. The game will then be restarted by choosing another leader for each group.

4. The following cards were put in a box.
a. A square
$132 \mathrm{~cm}=\ldots \ldots \mathrm{m} \ldots \ldots \mathrm{cm}$
b. A rectangle
c. 3 triangles

d.

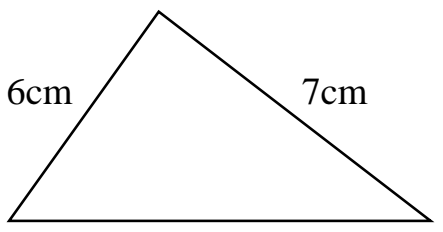

$8 \mathrm{~cm}$

Perimeter $=\ldots \ldots . . \mathrm{cm}$

e. A triangle

f. 2 Rectangles

g. Square

$2 \mathrm{~m} 53 \mathrm{~cm}=\ldots \ldots \ldots \mathrm{cm}$

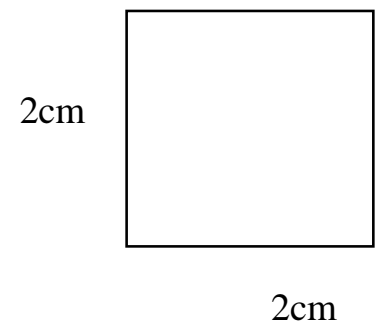

Perimeter $=\ldots \ldots \mathrm{cm}$

h. Rectangle

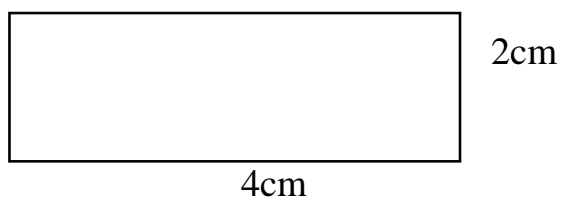

Perimeter $=\ldots \ldots . . \mathrm{cm}$

Each of these statements (itemized above) and drawings were placed inside a box, while each group leader picked them out one by one and read whatever is written there. Smaller square cards which had already been distributed to each pupil in the group are then picked by any pupil who recognized the position that matched the statement or diagram shown to the group members by the group leader. 
Pupils were left to play the game in groups, while the teachers and research assistants only ensure orderliness of pupils in playing the game. Posttest questions were administered after the pupils in the two schools used for experimental groups were taught the game and were left to play the game at their own pace. This is what the board looked like while the students were playing.

\section{Figure 1}

Example of what the board looked like while students were playing Bingo

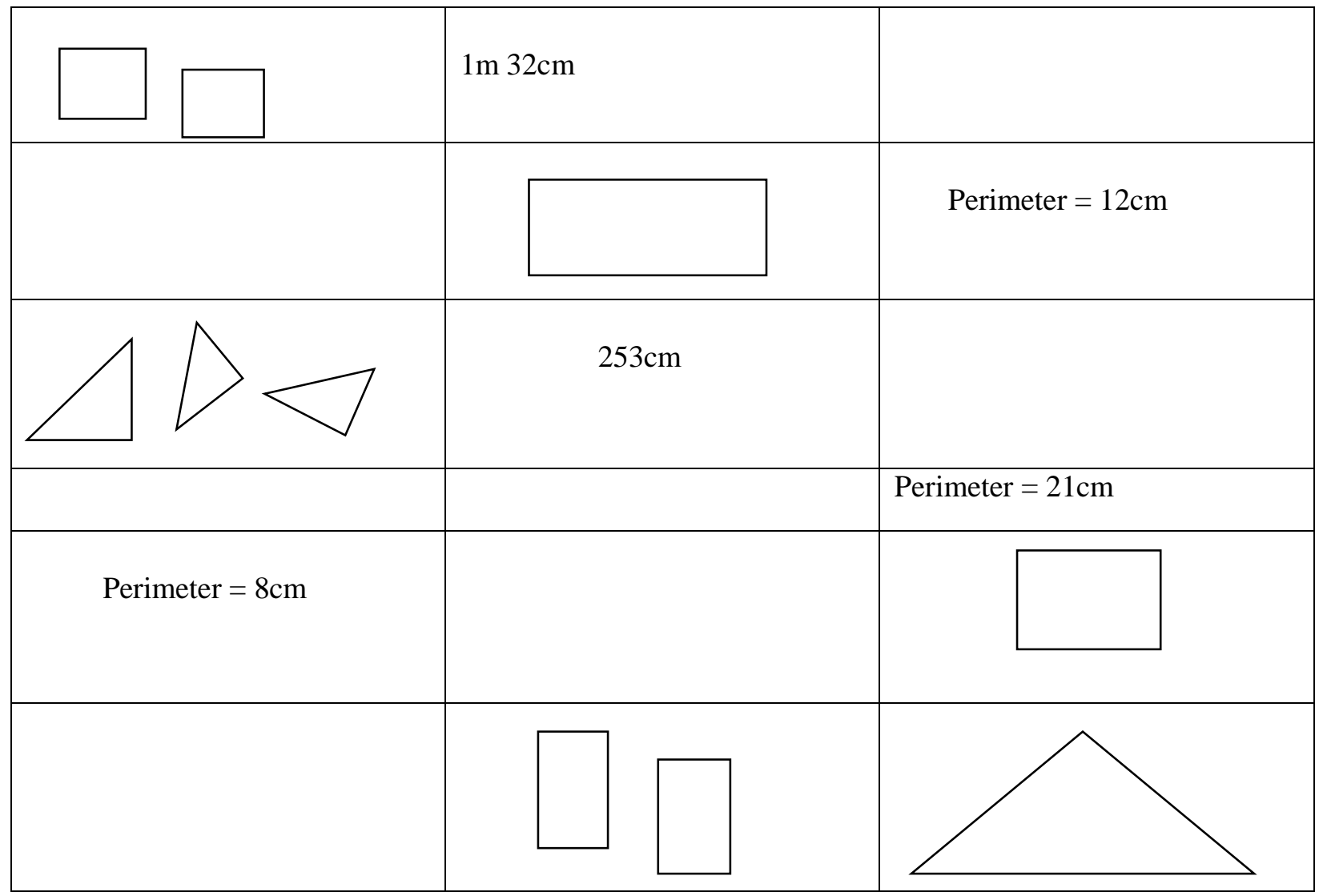

Note: Students were already placed in groups.

\section{Conventional strategy}

Conventional strategy was observed as control group for this study whereby the pupils in the group were not taught using Bingo game on the teaching of length, and perimeter of shapes, and figure.

\section{Methods of Data Analysis}

The data were analyzed using Analysis of Covariance (ANCOVA) with the pretest scores used as covariates. The Estimated Marginal Mean (EMM) was used to determine the magnitude of the mean scores of the different groups at 0.05 level of significance. The study lasted five weeks, while the treatment lasted four weeks and the administration of pretest and training of research assistants takes one week. Each of the research assistant taught concurrently at their various school (location). The researchers only move round to supervise the research assistants for doing the right thing. 
JISTE, Vol. 25, No. 1, 2021

\section{Results}

Table 1

Summary of $2 \times 3$ Analysis of Covariance Posttest Mathematics Achievement by Treatment by Quantitative Ability.

\begin{tabular}{lcccccc}
\hline Source & $\begin{array}{l}\text { Type Ill Sum } \\
\text { of squares }\end{array}$ & df & $\begin{array}{l}\text { Mean } \\
\text { Square }\end{array}$ & F & Sig. & $\begin{array}{l}\text { Partial } \\
\text { Squared }\end{array}$ \\
\hline Corrected Model & $3159.376^{\mathrm{a}}$ & 6 & 526.563 & 3.190 & .001 & 0.231 \\
Intercept & 1189.835 & 1 & 1189.835 & .976 & .024 & 0.713 \\
Pre-score (Covariate) & 3297.845 & 1 & 3297.845 & 4.283 & .013 & 0.356 \\
Treatment Group & 815.704 & 1 & 815.704 & 3.327 & $.007 *$ & 0.131 \\
Quantitative Ability & 1022.126 & 2 & 511.063 & 0.603 & $.002^{*}$ & 0.206 \\
Treatment Group & 987.939 & 2 & 493.969 & 1.543 & $.020^{*}$ & 0.214 \\
Quantitative Ability & 6926.179 & 106 & 65.341 & & & \\
Error & 14961.510 & 112 & & & & \\
Total & 9576.782 & 110 & & & & \\
Corrected Total & & & & & & \\
\hline
\end{tabular}

* significant at $0.05, \mathrm{R}$ Squared $=.411$ (Adjusted R Squared $=.383)$

$\mathrm{H}_{0} 1$ : There is no significant main effect of Bingo game instructional strategy on pupils' achievement in mathematics

From Table 1, the result indicated the posttest score on pupils' mathematics achievement using the pre-score as covariate revealed that there was significant main effect of treatment $\left(F_{(1,110)}=3.327\right.$, partial $\left.\eta^{2}=0.131\right)$. Therefore, $H_{0} 1$ was rejected.

\section{Table 2}

Estimated Marginal Means for Post-Achievement by treatment and Control Group

\begin{tabular}{lllll}
\hline Treatment & Mean & Std. Error & \multicolumn{2}{l}{ 95\% Confidence Interval } \\
& & & Lower Bound & Upper Bound \\
& & & 13.281 & 14.864 \\
Bingo Games Instructional Strategy (BGIS) & 14.07 & 0.399 & 5.889 & 7.334 \\
Conventional Strategy (CS) & 6.61 & 0.365 & \\
\hline
\end{tabular}

Table 2 revealed that mathematics pupils in Bingo Games Instructional Strategy (BGIS) treatment Group had the higher post-achievement score (14.07), while the Conventional Strategy (CS) Control Group had the least adjusted post-achievement mean score (6.61). This order is represented as BGIS > CS $\mathrm{H}_{0}$ 2: There is no significance main effect of quantitative ability on pupils' achievement in mathematics.

Table 1 revealed that there was significant main effect of quantitative ability $\left(\mathrm{F}_{(2,110)}=0.603\right.$, partial $\left.\eta^{2}=0.206\right)$. The mean score of low quantitative ability is $(\bar{X}=31.451$ and $\mathrm{SD}=9.892)$, medium quantitative ability is $(\bar{X}=50.000$ and $\mathrm{SD}=0.000)$ and the mean score of high quantitative ability is $(\bar{X}=56.904$ and $\mathrm{SD}=9.892$ ) and their mean difference is 36.169 . This result indicated that the high quantitative ability participants benefited from the treatment package more than the other participants counterpart. $\mathrm{H}_{0} 2$ is rejected.

$\mathrm{H}_{0} 3$ : There is no significance two-way interaction effect of treatment (Bingo game instructional strategy) and quantitative ability on pupils' achievement in mathematics

Finally, there was significant two-way interaction effect of treatment with quantitative ability of 
the participants $\mathrm{F}_{(2,106)}=1.543$, partial $\eta^{2}=0.214$. With these results, it shows that Bingo game instructional strategy was effective in enhancing pupils' mathematics achievement and the causal link between the treatment and criterion measure was determine by quantitative ability difference. $\mathrm{H}_{0} 3$ is also rejected.

\section{Discussion}

From the findings, results showed that the treatment enhanced pupils' mathematics achievement. This result agrees with the findings of (Ofodu and Lawal, 2011) that the treatment applied in their studies has shown positive effect the same as with the achievement of pupils involved in the study. This result also agrees with the results of Bala and Musa (2006) and Mustafa et al. (2011) who found the use of instructional materials (manipulatives) such as games, have positive effects on students' academic achievement. Butler, Miller, Crehan, Babbitt, and Pierce (2003) found that the impact of the Bingo game instructional strategy was able to foster primary school students' mathematics achievement.

There was a significant main effect in the posttest scores of pupils' quantitative ability exposed to treatment and conventional group. This indicates that pupils' quantitative ability helps in thinking and reasoning of learning mathematics when Bingo game instructional strategy was applied in teaching primary school pupils. This is contrary to the findings of Mansureh, Atsusi and Haiyan (2010). Their findings indicated that prior mathematics knowledge/computer skills did not play a significant role in achievement and motivation of the participants who played the games. Adu et al. (2009), in her findings, discovered the effectiveness of quantitative ability as the ability to execute tasks which are related to the handling of numbers.

Finally, results shows that there is significant interaction effect of treatment and quantitative ability in enhancing pupils' mathematics achievement among participants. This means that there is significant interaction effect in the posttest scores of treatment and quantitative ability as it enhanced pupils' quantitative ability among participants. Hence, this could be as a result of the fact that the intensity of treatment had significant impact on the participants irrespective of whether their ability is high, medium or low. In the aforementioned result, the result revealed that quantitative ability had significant main effect on the pupils' mathematics achievement of the participants, which is also demonstrated in this case, that the quantitative ability had significant interaction with treatment. Although for the treatment, Bingo game instructional strategy had incremental effects in the pupils' mathematics achievement of the participants either low, medium or high.

\section{Conclusion}

The study concludes that Bingo game instructional strategy enhanced pupils' achievement in length, perimeter, shapes and figures in Nigeria, with regards to their quantitative ability. Therefore, with rigorous research on mathematics as a subject or as a course of study among Nigerian students, there is hope that with the use of Bingo game instructional strategy, the situation can be changed for the better and better performance in accordance to the expectation of their teachers, parents, school authorities, examination board etc. 


\section{Recommendations}

In the light of this result, primary school mathematics teachers are encouraged to adopt Bingo game instructional strategy in teaching.

\section{References}

Adetunji F. O. (2000). A study of some Nigeria primary school teachers' attitude to mathematics. African Journal of Education Research, 6(1\&2), 93-99.

Adu, E. O., Ojelabi, S. A., \& Adeyanju, H. (2009). Quantitative ability as correlates of students' academic achievement in secondary school economics in Oyo State, Nigeria. African Research Reviews, 3(2), 322-333.

Akinboye, J. O. (1996). Psychological foundations of education in Africa (1st ed.). Stirling-Horden.

Akinsola, M. K., (1999). Factors inhibiting the learning of mathematics. In J. O. Obemeta, S. O. Ayodele, \& M. A. Araromi (Eds.), Evaluation of Africa in honour of E.A. Yoloye. (pp. 175-184). StilingHorden.

Akinsola, M. K., \& Tella, A. (2003) Effectiveness of individualistic and cooperative teaching strategies in learning geometry and problem solving in mathematics among junior secondary schools. Journal of Personality Study and Group Behaviours, 23, 95 - 105

Awofala, A. O. A., Fatade, A. O., \& Ola-Oluwa, S. A. (2012). Achievement in cooperative versus individualistic goal-structured junior secondary school mathematics classrooms in Nigeria. International Journal of Mathematics Trends and Technology. 3(1), 7-12.

Bala, A., \& Musa, B. (2006). Effect of the use of number base game on senior Secondary school achievement in number bases. Abacus: The Journal of Mathematical Association of Nigeria 3, 103-144

Butler, F. M., Miller, S. P., Crehan, K., Babbitt, B., \& Pierce, T. 2003. Fraction instruction for students with mathematics disabilities: Comparing two teaching sequences. Learning Disabilities Research and Practice, 18, 99-111.

Charles, D., \& McAlister, M. (2004). Integrating ideas about invisible playgrounds from play theory into online educational digital games. In M. Rauterberg (Ed.), Entertainment computing-ICEC 2004. (pp. 598-601) Springer.

Coco, A., Woodward, I., Shaw, K., Cody, A., Lupton, G., \& Peake, A. (2001). Bingo for beginners: A game strategy for facilitiating active learning. Teaching Sociology, 29(4), 492 -503.

Corti, K. (2006). Games based learning; a serious business applicationPIXE Learning. Retrieved from https://www.google.com/url?sa=t\&source=web\&rct=j\&url=https://www.cs.auckland.ac.nz/cours es/compsci777s2c/lectures/Ian/serious\%2520games\%2520business\%2520applications.pdf\&ved= 2ahUKEwjPILCTtdHxAhVF8eAKHcMOB_IQFjABegQIJxAC\&usg=AOvVaw1W61_3f6HxdD gsNLg71QNC 
Csikszentmihalyi, M. (1990). Flow: The psychology of optimal experience. Harper and Row.

Gee, J. P. (2005). What video games have to teach us about learning and literacy. Palgrave Macmillan.

Haramati, A. (2000). Teaching physiology: filling a bucket or lighting a fire? The Physiologist, 43, 117121.

Holland, W., Jenkins, H., \& Squire, K. (2002). Theory by design. In Perron, B. \& Wolf. M. (Eds.), Video gametTheory reader (pp. 25-46). Routledge

Ifamuyiwa, A. S. (2005). Effect of self and cooperative instructional strategies on senior secondary school (SSS) students' learning gains in mathematics. (Doctoral dissertation), University of Ibadan, Ibadan.

Jones, A., \& Issroff, K. (2005). Learning technologies: Affective and social issues in computer-supported collaborative learning. Computers and Education. 44, 395-408.

Ke, F. \& Grabowski, B. (2007). 'Gameplaying for maths learning: Cooperative or not?' British Journal of Educational Technology, 38(2), 249-259.

Khoo, A. \& Gentile, K. A. 2005. Problem-based learning in the world of digital games. In O. Tan (Ed.), Problem-based learning in elearning breakthroughs. (pp. 97-129). Thompson Learning.

Kiili, K. (2005). Educational game design: Experiential gaming model revisited. Research Report 4. Retrieved from http://amc.pori.tut.fi/publications/EducationalGameDesign.pdf

Mansureh, K., Atsusi, H., \& Haiyan, B. (2010). The effects of modern mathematics computer games on mathematics achievement and class motivation, Retrieved from: www.elsevier.com/locate/compedu

Mustafa, J., Khan, A., \& Ullah, A. (2011). Investigating students' achievement in mathematics through non-technological game based teaching. International Journal of Scientific Research in Education, $4,151-164$.

National Council of Teachers of Mathematics (2000). Principles and standards for school mathematics. National Council of Teachers of Mathematics.

Obodo, G. C. (1997). Principles and practice of mathematics education in Nigeria. Enugu General Studies Division, ESUT, 7-15.

Ofodu, O. O., \& Lawal, R. A. (2011). Cooperative instructional strategies and performance levels of students in reading comprehension. Journal of International Education, 3(2), 103-107.

Okafor, C. F., \& Anaduaka, U. S. (2013). Nigerian school children and mathematics phobia: How the mathematics teacher can help. American Journal of Educational Research, 1(7), 247 - 251.

Onabanjo, C. F. (2004). A Survey of Some Behavioural and Attitudinal Factors Affecting Senior Secondary School Female Students' Mathematical Ability and Achievement. A Ph.D Research Post-Field Report, University of Ibadan. 
Osokoya, M. M. (2005). Science education and national development in Nigeria: Trends and strategies for the improvement of teaching-learning of science in Nigeria. African Journal of Historical Sciences in Education. 1(2), 19-31.

Pehkonen, E. (1993). What are Finnish teacher educators' conceptions about the teaching of problem solving in mathematics? European Journal for Teacher Education 16(3), 237-256.

Prensky, M. (2001). Digital game-based learning. McGraw-Hil.

Pulos, S., \& Sneider, C (1994). Designing and evaluating games for teaching science and mathematics: An illustration from coordinate geometryll. Focus on Learning Problems in Mathematics, 16(3), 2342.

Rigby, S., \& Ryan, R. (2007). The player experience of need satisfaction PENS model. Retrieved from ftp://ftp.immersyve.com/PENS_Sept 07.pdf

Shofoyeke. A. D. (2012). The impact of teaching methods on pre-primary school pupils' learning achievement in protection issues in selected nursery and primary schools in Ondo west local government. Journal of Elementary Education, 25(2), 45-60.

Vlachopoulos, D. \& Makri, A. (2017). The effect of games and simulations on higher education: a systematic literature review. International Journal Educational Technology in Higher Education., 14(22), 1-33.

West African Examinations Council - 2015. Chief Examiner's reports (Nigeria) SSCE, May/June examinations.

\section{Authors}

Adedeji Tella, $\mathrm{PhD}$, is a Senior Lecturer at the University of Ibadan, Faculty of Education, Department of Sciences and Technology Education, Nigeria. His research interests are within the areas of mathematics education, curriculum and instructions, science education, ICT in mathematics, course design, data analysis, curriculum review and development in mathematics and sciences and its pedagogy.

Felicia Motunrayo Fatoki is a lecturer at Federal School of Statics, Ibadan, Nigeria. She is a seasoned mathematics teacher and she has taught in almost every level of education in Nigeria. She has a wealth of experiences in game- based learning and in mathematics pedagogy. 